\title{
Crisis Decision-Making During Hurricane Sandy: An Analysis of Established and Emergent Disaster Response Behaviors in the New York Metro Area
}

\author{
Thomas Chandler, PhD; David M Abramson, PhD, MPH; Benita Panigrahi, MD, MS;
} Jeff Schlegelmilch, MPH, MBA; Noelle Frye, MA

\section{ABSTRACT}

Objective: This collective case study examined how and why specific organizational decision-making processes transpired at 2 large suburban county health departments in lower New York State during their response to Hurricane Sandy in 2012. The study also examined the relationships that the agencies developed with other emerging and established organizations within their respective health systems.

Methods: In investigating these themes, the authors conducted in-depth, one-on-one interviews with 30 senior-level public health staff and first responders; reviewed documentation; and moderated 2 focus group discussions with 17 participants.

Results: Although a natural hazard such as a hurricane was not an unexpected event for these health departments, they nevertheless confronted a number of unforeseen challenges during the response phase: prolonged loss of power and fuel, limited situational awareness of the depth and breadth of the storm's impact among disaster-exposed populations, and coordination problems with a number of organizations that emerged in response to the disaster.

Conclusions: Public health staff had few plans or protocols to guide them and often found themselves improvising and problem-solving with new organizations in the context of an overburdened health care system (Disaster Med Public Health Preparedness. 2016;page 1 of 7).

Key Words: public health, Hurricane Sandy, crisis decision-making, leadership, emergent behavior

$\mathrm{H}$ urricane Sandy made landfall along the northern Atlantic Coast of the United States on October 29, 2012, affecting 24 states in a disaster that covered the largest land mass in US history, stretching from Maine to Florida. More than 130 people were killed on the US eastern seaboard, and nearly $\$ 71$ billion dollars in damages were reported. ${ }^{1}$ The hurricane struck the New York metropolitan area, causing large-scale evacuations, while also severely damaging more than 120,000 housing units. The 2 suburban county health departments that were the focus of this study are in close proximity to New York City and are home to a combined population of more than 2.5 million residents. During Hurricane Sandy, these counties faced wind gusts up to $90 \mathrm{mph}$ and storm surges up to 14 feet. $^{2}$

Although the wind and water destruction caused by Hurricane Sandy was somewhat predictable, the subsequent nor'easter prolonged existing power outages and fuel and heating shortages that lasted days to weeks and that subsequently placed an enormous strain on the public health system response. Even though many public health professionals and health care delivery providers were forced to evacuate and were victims of the storm themselves, hundreds of professionals worked around the clock to provide support for emergency operations during Hurricane Sandy. Ensuring continuity of essential public health functions necessitated multiagency, multisectoral coordination with traditional and nontraditional stakeholders, including regional hospitals, nursing homes, shelters, transportation organizations, and private businesses from across the health system.

As noted in this study, the local public health disaster response to Hurricane Sandy was adaptive. Before the storm, both agencies planned their organizational responses using the traditional incident command system and assigned leadership roles (eg, operations, logistics, finance) more than 72 hours in advance. Still, much of the response proved challenging, including the duration of the response, the ability for the workforce to respond, and emergent challenges in staffing a special needs shelter.

There is still much to learn about individual and organizational decision-making in public health agencies threatened by coastal storms and other mega-disasters. 
As noted by Comfort and Resodihardjo, ${ }^{3}$ interactions among public health staff under rapidly altering conditions are not well understood. The primary aim of this article was to explore the crisis decision-making processes carried out by 2 large suburban health departments in responding to a natural disaster, while also examining the intersecting relationships among other established and emerging organizations across the health system. We investigated these themes through the theoretical lens of Dynes' disaster typology, which distinguishes between established and emerging decision-making processes. The findings presented here are important in that they build on the disaster research literature pertaining to crisis decision-making.

\section{Impetus for This Study}

Many of the challenges that the 2 health departments had in carrying out crisis decision-making efforts with other organizations during Hurricane Sandy were outlined in a video-recorded focus group discussion with 6 county public health commissioners from lower New York State that was held in January 2013 at Columbia University and was moderated by one of the investigators (DMA). ${ }^{4}$ Statements made during this initial focus group discussion highlighted several intra-agency coordination problems in relation to the Public Health Emergency Preparedness (PHEP) Capabilities, such as biosurveillance, community resilience, medical countermeasures and mitigation, incident management, information management, and surge management. Descriptions of the unforeseen burdens placed on the regional public health sector subsequently became the focus of a proposed Centers for Disease Control and Prevention (CDC)-funded study awarded in September 2013. Although there is a substantial amount of public health research literature on crisis decision-making, the authors noted that there are few studies specifically focusing on extreme coastal storms. A primary aim of this study was thus to explore the unique ways in which various organizational disaster response strategies were carried out.

\section{Theoretical Framework}

The investigators relied upon a framework of emergent organizations and roles developed by Dynes (1970) as a means to capture the process and evolving nature of organizational behavior during the emergency period of a disaster. Dynes' typology classifies organizations along 2 dimensions: tasks and structure (Figure 1).,

According to Dynes, tasks can be categorized as either regular or irregular and organizational structure is characterized as old or new, resulting in 4 types of organized responses to disasters. Type I organizations are established institutions that rely upon a previously recognized structure and carry out routine tasks during disasters. For example, police and fire departments are well-established organizations whose routine mission is one of emergency response and who will respond in this fashion to a variety of disasters. Type II entities are

\section{FIGURE}

\section{Dynes' Typology Classifies Organizations Along 2 Dimensions: Tasks and Structure.}

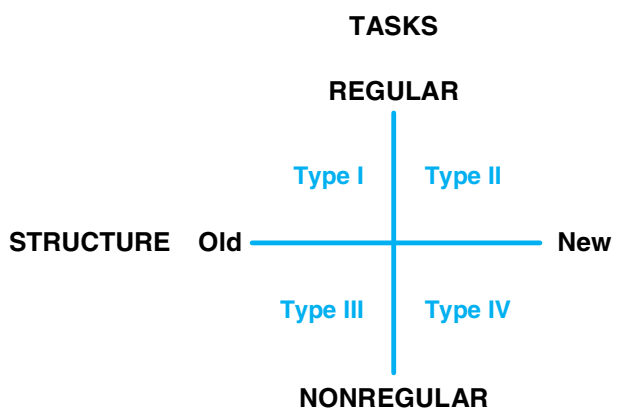

Type I, established organized response ; Type II, expanding organized response; Type III, extending organized response; Type IV, emergent organized response.

institutions that expand their organizational structure in order to quickly respond to disasters, as they also carry out regular tasks. However, in so doing so, they depend on new structural arrangements. For instance, a social services agency is routinely staffed by professional workers, but following a disaster the structure may expand to incorporate volunteers and interactions with other emerging groups. Type III, or extending organizations, are usually not anticipated as being responder organizations. They are characterized by a preexisting structure, but during disasters they perform irregular tasks. For example, a private bus company might be involved in transporting nursing home residents to higher ground during a hurricane evacuation. Lastly, Type IV, or emergent organizations, involve a completely new structure and irregular tasks. Overall, these organizations do not materialize until the disaster takes place. ${ }^{6}$ A recent example would include a community organization with a strong online presence, such as Occupy Sandy, that develops an online crowdsourced map to assist residents in finding open pharmacies during a disaster.

Although the tasks carried out by the 2 health departments were part of an existing (Types I and II) organizational structure, the authors hypothesize that these agencies were nonetheless faced with the need to develop and adapt to new structural arrangements to handle various emerging crises. Consequently, each public health agency navigated both horizontally and vertically throughout Dynes' topology, carrying out regular and irregular tasks while also functioning within old and new structures. ${ }^{6}$ The public health agencies could thus be considered as organizations that sought to provide linkages among other established and emergent entities that had often never interacted before. This article explores how and why these decisions and relationships were formulated during the response to Hurricane Sandy. We also examine whether the emergent nature of disaster response 
requires a reconceptualization of Dynes' typology to better encompass the role of local public health departments as adaptive organizations needing to continually respond to unpredictable and rapidly changing conditions.

\section{METHODS}

A qualitative collective case study approach was used to evaluate the public health response based on triangulation of one-on-one interviews with 30 key informants and 2 focus groups with 17 participants in total. Each interview was approximately 2 hours and the 2 focus groups lasted for 1 hour. The authors also used content analysis of situation reports, annual reports, after action reports, and social media posts to validate the qualitative findings.

The collective case study approach allowed for the detailed examination of the public health workers at the sites in which they worked and helped guide the investigation toward developing an in-depth understanding of how the staff made complex decisions regarding Hurricane Sandy.

\section{Sample and Recruitment}

The 2 suburban county public health agencies were invited to participate in this study given that they resided in coastal zones that had experienced catastrophic flooding and wind damage from Hurricane Sandy. Likewise, these agencies interacted with New York State's Healthcare Evacuation Center during and after the storm, which coordinated bed placements for evacuees from New York City. The investigators sought to document how the evacuation process unfolded and impacted the lower New York State county public health agencies along with other organizations they collaborated with.

The authors identified and selected a purposive sample of key public health senior staff at the agencies to interview. Organizational charts were provided by the 2 agencies to help guide the selection process. Public health agency liaisons did not make any recommendations of staff to include in the actual interviews. The investigators selected interviewees on the basis of their involvement in the strategic operations and tactical decisions arising in preparation for and response to Hurricane Sandy, in addition to their day-to-day responsibilities. Informants were also selected on the basis of their role in the incident command system. For the 2 focus groups, the investigators contacted nursing home administrators in both counties to discuss their experiences in collaborating with the public health agencies during Hurricane Sandy. These participants were selected on the basis of their level of interaction with the public health agencies during the storm, along with the level of damage experienced at the nursing home facilities. All of the nursing home administrators who participated had direct contact with their respective public health agency on evacuation protocols and patient transfer issues, which ultimately became emerging challenges of interest to this study. Likewise, all of the nursing home administrators worked in the coastal areas of each county that had experienced catastrophic flooding.

\section{Data Collection and Analysis}

Each of the key informant interviews and focus groups was audiotaped and transcribed. An extensive codebook was developed to categorize the qualitative data, with coding elements drawn from the CDC's PHEP Capabilities and the National Health Security Preparedness Index. The authors identified coding elements and used the ATLAS.ti qualitative software program, version 7 (Scientific Software Development $\mathrm{GmbH}$, Berlin, Germany) to assign codes and sort the text. The coding themes were iteratively identified in domains such as community resilience, countermeasures and mitigation, incident management, information management and surge management, and biosurveillance. Subcodes were developed, such as compliance, persuasion, responsibility, and expertise. Content analysis of situation reports, annual reports, after action reports, and social media posts helped to facilitate validation of data through cross-verification from different sources.

\section{RESULTS}

Hurricane Sandy, which struck New York Harbor on October 29,2012 , resulted in a number of routine and unforeseen challenges for the 2 New York State county public health agencies. Navigating around these challenges required decision-making within the leadership structure by designated leaders and new ones. When considering the disaster response within Dynes' Typology, there were a multitude of examples of the ways in which public health staff carried out tasks in each quadrant.

\section{Type I: Established Organized Response}

There were many examples of how the public agencies relied upon an existing structure to carry out routine tasks during the disaster, as staff communicated with the police, fire, and emergency services departments on various issues noted in Table 1 . The majority of these disaster response coordination efforts transpired at the county Emergency Operation Centers, as public health workers staffed the Emergency Support Function - Public Health (ESF-8 health) desk, for which coordination with other county agencies was anticipated as part of the response.

\section{Type II: Expanding Organized Response}

Public health staff also directly responded to the disaster, as they relied upon new structural arrangements with other federal, state, and nonprofit organizations who assisted in the response on specific tasks, as part of existing disaster plans and newly formed Memoranda of Understanding. Within this quadrant type, the expansion of volunteer services, particularly from the Medical Reserve Corps, became much 
Examples of the Ways in Which Public Health Staff Carried Out Tasks in Quadrant Type I: Established Organized Response

Public Health Agency Task

Conducting restaurant inspections and identifying generator misuse Reestablishing electrical power generation and telecommunications Contacting suppliers and vendors to ensure continuity of essential services Maintaining vital records management
Relationships With Other Organizations

Police, fire, and emergency services Utility companies, Internet service providers Private medical suppliers

Off-site records storage facilities

\section{Examples of the Ways in Which Public Health Staff Carried Out Tasks in Quadrant Type II: Expanding Organized Response $^{\mathrm{a}}$}

\section{Public Health Agency Task}

Managing surge of MRC volunteers

Expanding shelter facilities and services with nonprofit partners Expanding clinical services to include Tdap vaccinations

Staffing the county emergency operations center ESF-8 desk for 12-hour shifts

\author{
Relationships With Other Organizations \\ Assistant Secretary for Preparedness and Response (ASPR), US Department of \\ Health and Human Services (HHS), regional universities \\ Red Cross, faith-based nonprofit organizations \\ CDC, New York State Department of Health, private medical suppliers \\ County Office of Emergency Management, New York State Department \\ of Health
}

${ }^{a}$ Abbreviations: CDC, Centers for Disease Control and Prevention; ESF-8, Emergency Support Function - Public Health; MRC, Medical Reserve Corps.

\section{TABLE 3}

\section{Examples of the Ways in Which Public Health Staff Carried Out Tasks in Quadrant Type III: Extending Organized Response}

\section{Public Health Agency Task}

Staffing special needs shelters with clinicians and administrative support from other organizations

Developing memoranda of understanding with private businesses from across the health system to help manage and maintain special needs shelter

Developing memoranda of understanding with public transportation agencies from across the health system to assist in nursing home evacuations

Gaining access to new medications to support special needs shelter patients

\section{Relationships With Other Organizations}

Disaster Medical Assistance Team (DMAT), Red Cross

Portable laundry businesses, oxygen supply companies, visiting nurse services, medical waste companies

County transportation agencies, private bus companies, nursing home liaisons

Health care delivery, pharmacies, drug stores, medical supply companies more pronounced. The primary tasks and structural arrangements are listed in Table 2.

\section{Type III: Extending Organized Response}

As the disaster unfolded, interactions with emergent organizations became more prominent and usually involved crisis decision-making procedures with senior staff at each agency. Decision-making pertained to coordination with private organizations who were not previously expected to respond to disasters but who were suddenly contacted for assistance with irregular tasks. For the 2 health departments, many of these decisions occurred during the staffing and management of special needs shelters, in which unforeseen needs, such as gaining access to new medications and laundering clothing became urgently needed. Senior staff were able to develop immediate Memoranda of Understanding with local businesses, public transportation companies, and nonprofits to secure access to resources. The primary tasks and structural arrangements are listed in Table 3.

\section{Type IV: Emergent Organized Response}

As Hurricane Sandy intensified and New York City hospitals began to evacuate patients to neighboring counties, a number of emergent problems came to the fore regarding the transport and bed placement of patients, many of whom were elderly, with limited physical, sensory, and cognitive abilities. In several instances, the county public health agencies were not aware that large numbers of elderly patients were entering 
Examples of the Ways in Which Public Health Staff Carried Out Tasks in Quadrant Type IV: Emergent Organized Response $^{\mathrm{a}}$

\section{Public Health Agency Task}

Responding to immediate patient bed availability requests from evacuating hospitals and nursing home facilities

Responding to frail, elderly homebound residents identified by door-to-door public health surveyors

Delivering medical equipment and supplies from evacuated nursing home patients to new facilities

Coordinating other housing arrangements for special needs shelter patients beyond 30 days

Responding to face-to-face and online rumors of disease and crime that negatively impacted the willingness of community groups to interact with the public health agencies

\section{Relationships With Other Organizations}

Regional hospitals, EMS, medical transport organizations, New York State Healthcare Evacuation Center, New York City Department of Health

Disaster Medical Assistance Team (DMAT), MRC, visiting nurse services

Private nursing homes, private transportation companies

Hotels, nursing and assisted-living facilities, homeless shelters and FEMA facilities

Community and faith-based organizations, television- and radio-based media, social media

${ }^{a}$ Abbreviations: EMS, emergency medical services; FEMA, Federal Emergency Management Agency; MRC, Medical Reserve Corps.

their health system from New York City. Consequently, senior-level public health staff located in the surrounding counties were faced with a surge in requests to house and care for new evacuees, just as plans were being made to evacuate other nursing home facilities within their suburban counties. Two weeks after Hurricane Sandy struck the region, these emergent issues only became more pronounced, with an increasing reliance on the public health agencies' expertise, particularly when dealing with elderly nursing home residents being transferred to special needs shelters or other nursing home facilities. Given that many of these residents lacked medical records or the specialized equipment that they depended on, the public health agencies had to immediately partner or coordinate services with a multitude of public and private organizations listed in Table 4.

\section{DISCUSSION}

For the 2 public health agencies during Hurricane Sandy, the need for integration of the traditional response agencies with emergent communities intensified as the number of organizations engaged in response operations increased and the range of problems they confronted widened. Since most organizations in the damaged areas were affected, regional hospitals, nursing homes, special needs shelters, public transportation companies, and private businesses became participants in the response system, with the public health agencies often establishing new relationships among them.

When dealing specifically with emergent challenges, such as direct communication with elderly and frail residents, it was evident in our examination of the data that the public health agencies often lacked situational awareness about where vulnerable populations were located or what specific medical needs they had. After all, because of previous concerns about access to private medical information, the agencies did not possess Medicare health insurance claims or registries to identify
FIGURE 2

Reconceptualization of Public Health Agencies' Role in Dynes' Typology.

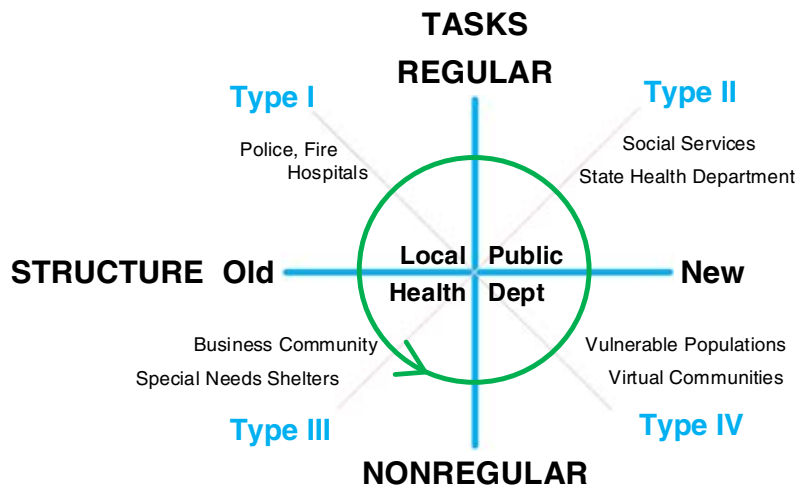

potentially vulnerable people, such as those dependent on oxygen equipment and ventilators. Consequently, public health staff were sometimes faced with the mounting challenge of coordinating patient care in an overburdened health system.

When considering this phenomenon within Dynes' typology, the public health agencies faced considerable burdens as they increasingly dealt with unforeseen challenges due to the prolonged loss of power and fuel, combined with limited situational awareness of impacted populations. Although the public health agencies were principally "existing" organizational structures whose tasks shifted from existing to expanding activities, in order to adopt to the chaotic disaster environment and coordinate multiple agencies, they often found themselves extending their organizational structures in a number of innovative and emergent ways. Furthermore, as boundary-spanning organizations, as illustrated in Figure 2, the public health agencies often provided linkages among 


\section{FIGURE 3}

\section{Relationship of Emergent Strategies to Intended Strategies.}

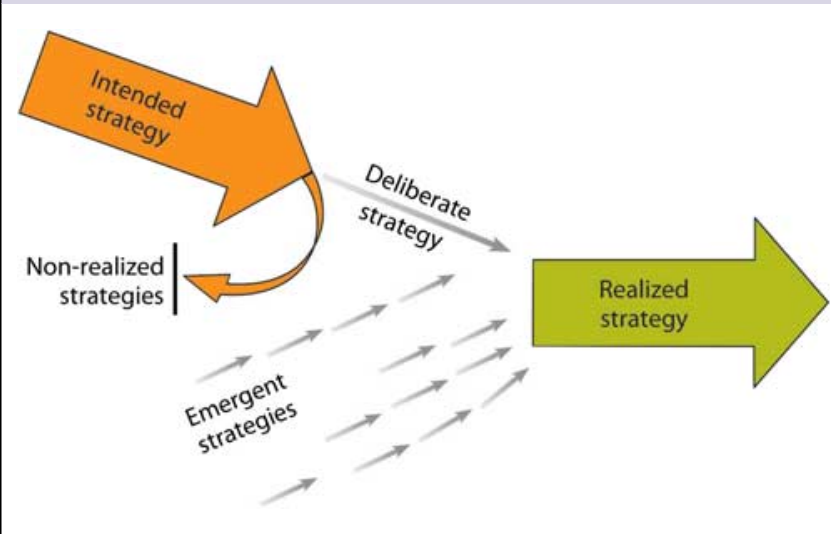

From Carpenter et al, 2009, with permission. ${ }^{7}$

other established and emergent entities that had often never interacted before.

Dynes has asserted that the seemingly insurmountable challenges posed by prioritization and resource allocation during emergent events can be ameliorated to an extent by reconceiving of disaster response processes, placing further value on instantaneous crisis decision-making in a manner that is less hierarchical. ${ }^{6}$ It is also necessary to consider Dynes' model as part of a cross-disciplinary research continuum that recognizes that emergent strategies need to accommodate baseline planning as well as react to immediate changes (Figure 3). ${ }^{7}$ This framework identifies that strategies are developed with primary intentions based on the context in which they were developed, but factors change that impact the decision-making landscape and alter the actual realized strategy.

Expanding on this, Raynor $^{8}$ notes that there is often a "Strategy Paradox," with a need to face downstream consequences before sufficient data are available to actually make informed decisions. To escape this paradox, he asserts that the role of the strategic planner is to make commitments that create and preserve options available to the organization as new information is released. This requires the integration of defining the strategic dimensions that are relevant to an organization and understanding likely extremes of how these dimensions could play out. ${ }^{8}$

While there are many different models for navigating this, emergency management and public health organizations operate very similar to "networked organizations." Networked organizations are made up of formal and information systems for collaborations and coordination. They are designed for optimal flexibility and adaptability in uncertain environments. While there may be more rigid hierarchies within certain units, the relationships between units are inherently collaborative. ${ }^{9,10}$

With an appropriate adaptation of these concepts to the vernacular of operations within the field of public health, the tools established in support of these concepts become available to create real solutions to the decision-making leadership and decision-support needs of public health response organizations. This includes identifying the development of effective and appropriate information management systems strategies as well as developing decision-making criteria designed to ensure decisions are made at the lowest level in the response hierarchy as possible. ${ }^{11}$

\section{CONCLUSION}

As a "mission area," public health is not neatly circumscribed. Other emergency support functions, such as transportation (ESF-1), communications (ESF-2), and firefighting (ESF-4) generally have clear organizational and task-specific boundaries. Given public health's "mission" of ensuring a population's health and welfare and of the complex enterprise of public and private institutions that routinely support this mission, it is nearly inevitable that traditional incident command structures are inadequate to the task of managing and coordinating all the activities involved in maintaining the public's health. Dynes developed the typology of routine and emergent organizations as a means of describing such complex organizational behavior and then offered a further critique of the conventional "military model" of command-andcontrol which he described as often unable to accommodate both routine and emergent organizations and behaviors. ${ }^{6}$ Among Dynes' recommendations are to develop "problemsolving models" rather than military models and to create incident management systems that allow for "decentralized and pluralistic decision-making" and that permit what he referred to as "open system[s] of coordinated effort."

This analysis of "extending" and "emergent" public health response systems during Hurricane Sandy echoed analyses of public health response from other disasters, particularly Hurricane Katrina. ${ }^{12}$ As occurred with public health officials in Louisiana and Mississippi after Hurricane Katrina, the public health officials in the New York metropolitan area were confronted with interdependent systems, lapses in leadership or judgment at local health institutions, and competing agendas. Consider that during Hurricane Sandy, several hospitals discharged their noncritical patients home in the days leading up to the storm. This created a "surge" of community-based patients for home health care and visiting nurse agencies that would soon be exacerbated by the fuel and power outages. This home health workforce was not deemed to be "essential personnel" and was often unable to get priority access to fuel and supplies. Community-based patients were often unable to manage their health care, often including a need for medications of complex therapeutic 
regimens, and some sought help in over-burdened special needs shelters. The tasks of identifying this community-based need, coordinating a response of supplies and personnel, and ensuring that this "extended" response system was working fell to public health. As occurred during Hurricane Katrina, the public health practitioners during Hurricane Sandy were often overwhelmed by the magnitude of the need and were also often operating in environments of insufficient situational awareness.

The complexity of managing the public health "mission space" was certainly illustrated in the experiences of these 2 large county public health departments during and in the aftermath of Hurricane Sandy. Some of the innovations that emerged from these experiences also point the way toward solutions. In one of the counties, in the months after the storm, the public health commissioner began meeting with a group of nursing home operators whose institutions were situated in flood-prone coastline communities. These nursing home operators welcomed the opportunity to plan for future emergencies and recognized the elements of their operations that had been "expanded" and "extended" during Hurricane Sandy and their dependence upon their public health agencies for assistance.

Although Dynes' typology was conceived long ago, the role of public health and its interactions with established and emergent entities within the typology remains unclear and in flux, thus warranting further investigation. As this study has shown, public health agencies are sometimes considered firstresponder organizations, while they also deal with emerging crises that demand unique forms of decision-making with previously unidentified community groups and vulnerable populations.

\section{About the Authors}

National Center for Disaster Preparedness, Earth Institute, Columbia University, New York, New York (Dr Chandler, Dr Panigrahi, Mr Schlegelmilch); NYU College of Global Public Health, NYU Medical Center Department of Population Health, New York, New York (Dr Abramson); and Yale New Haven Health System Center for Healthcare Solutions, New Haven, Connecticut (Ms Frye).
Correspondence and reprint requests to Thomas Chandler, PhD, National Center for Disaster Preparedness, Earth Institute, Columbia University, 215 West 125th Street, Suite 303, New York, NY 10027 (e-mail: tec11@columbia.edu).

\section{Acknowledgments}

The authors thank the 2 public health departments noted in this study for their cooperation in allowing staff to be interviewed. The research described in this project was funded under a CDC-funded Cooperative Agreement number 1U01TP00589-01. The views and recommendations expressed in this article are solely those of the authors.

\section{REFERENCES}

1. National Oceanic and Atmospheric Administration. Service Assessment: Hurricane/Post-Tropical Cyclone Sandy, October 22-29, 2012. http://www.nws.noaa.gov/os/assessments/pdfs/Sandy13.pdf. Published May 2013. Accessed April 7, 2016.

2. Smith M. Sandy wreaks havoc across Northeast; at least 11 dead. CNN. http://www.cnn.com/2012/10/29/us/tropical-weather-sandy/. Published October 30, 2012. Accessed April 7, 2016.

3. Comfort LK, Resodihardjo SL. Leadership in complex adaptive systems. International Review of Public Administration. 2013;18(1):1-5. http://dx. doi.org/10.1080/12294659.2013.10805236.

4. Abramson DA. Hurricane Sandy roundtable: A conversation among local public health leaders; Jan. 17, 2013 [video recording]. http:// ncdp.columbia.edu/microsite-page/hurricane-sandy-october-2012/sandyrecovery-1-year-later/. Accessed April 7, 2016.

5. Dynes RR. Organized Behavior in Disaster. Lexington, MA: Heath; 1970.

6. Dynes RR. Disaster reduction: the importance of adequate assumptions about social organization. Sociol Spectr. 1993;13(1):175-192. http://dx. doi.org/10.1080/02732173.1993.9982022.

7. Carpenter M, Bauer T, Erdogan B. Principles of Management. Washington, DC: Flat World Knowledge; 2009.

8. Raynor ME. The Strategy Paradox. Why Committing to Success Leads to Failure and What to Do About It. New York: Doubleday; 2007.

9. Schlegelmilch J, Albanese J. Applying business intelligence innovations to emergency management. J Bus Continuity Emerg Plann. 2014;8(1):31-40.

10. Comfort LK, Okada A. Emergent leadership in extreme events: a knowledge commons for sustainable communities. International Review of Public Administration. 2013;18(1):61-77. http://dx.doi.org/10.1080/12294 659.2013.10805240.

11. Akselrod H, Mercon M, Kirkeby Risoe P, et al. Creating a process for incorporating epidemiological modelling into outbreak management decisions. J Bus Continuity Emerg Plann. 2012;6(1):68-83.

12. VanDevanter N, Leviss P, Abramson DA, et al. Emergency response and public health in Hurricane Katrina: what does it mean to be a public health emergency responder? J Public Health Manag Pract. 2010;16(6): E16-E25. http://dx.doi.org/10.1097/PHH.0b013e3181d8bbb2. 